\title{
Vocabulary Instruction and Learning: A Commentary on Four Studies
}

\author{
Jenifer Larson-Hall \\ University of Kitakyushu \\ https://doi.org/10.7820/vli.v08.1.Larson-Hall
}

\begin{abstract}
Four papers were presented by Shusaku Kida, Magda Kitano and Katsuhiro Chiba, Tim Stoeckel, and Raymond Stubbe. In this article, my thoughts about the issues raised in these thought-provoking papers about vocabulary resource processing allocation and the Type of Processing Resource Allocation (TOPRA) model, the use of flashcards in vocabulary learning, an empirical evaluation of the New General Service List (NGSL), and the use of yes-no checklists for multi-word units are given. The first paper provided some theoretical underpinnings for thinking about vocabulary acquisition, while the last three papers were valuable for their extremely timely and practical examination of issues that are highly important for the acquisition of vocabulary.
\end{abstract}

I have four children, all bilinguals. Raising my children (and I am not done yet) is the hardest but most rewarding work that I have done in my life. You might wonder, though, why I mention raising children in the context of discussing the four papers we have heard today. I mention it because to raise four children without going crazy means that you must be extremely organized and practical, and I like to think I am. In the same vein, I like practical research that has details about the study methodology, concrete numbers and results, and I like to ask practical questions that relate to how research can apply to real-life problems.

I am pleased and honored to be asked to comment on these studies today. All of them are very interesting. Three out of the four studies I will discuss today are empirical studies and can be evaluated on the strength of their conceptual design, methodology, and results. The fourth study, Shusaku Kida's paper, "Foreign Language Vocabulary Learning and the Type of Processing-Resource Allocation Model," is not an empirical study but rather a summary of a type of approach to studying vocabulary learning, namely, the TOPRA model. Kida's paper gave me food for thought and got me the most engaged in thinking about a number of overall issues.

I actually hope that the issues I bring up here, inspired by all of the papers, will be very practical issues that we can think about. 


\section{Practical question 1: How can we judge that a word has been learned?}

The biggest issue I came away with was how to judge that a word has been learned. The TOPRA model that Kida examines proposes that at least at the beginning stages of learning a language, "the learning of word form is more important than the learning of meaning." Kida is arguing that since the meaning of the word in the L1 is already known, what needs to be learned is not the meaning of the word itself, but the mapping from the L2 word (and its form) to the L1 word. Kida invokes Barcroft's TOPRA model that says there will be tradeoffs in processing ability so that trying to add another component to the memory exercise of forming those L1-L2 mapping links, such as a semantic evaluation component (like evaluating whether the word is pleasant or not) or a structural evaluation component (such as counting the number of letters in the word), is going to take away from, rather than add to, the ability to make that mapping link. Kida and Barcroft (2017) make the pedagogical recommendation to not add any extra processing demands such as these when asking language learners to learn new words. They also make the point that learning a word is a process that develops in stages.

Of course, the question of how we judge whether a word has been learned is not limited to Kida's paper. Magda Kitano and Katsuhiro Chiba also explore the question of what kind of learning is the most effective way for Japanese learners to acquire vocabulary in their paper entitled "Comparing the Effectiveness of Word Cards and List Learning with Japanese Learners of English.” Of course, to answer the question we must also think about what it means to have acquired or learned vocabulary. The answer to this question will dictate what kinds of evidence we will find convincing to answer questions like whether "list learning" or "word card (flashcard)" learning is more effective.

Would we like to say that someone has learned a word if they can correctly give an L1 or L2 translation to a word immediately after studying the word? I think none of us would like to say that this is acquisition, because acquisition seems to mean it is something that we can use in the course of our daily life. We do not talk about "acquiring" an ice cream cone, because that is quickly bought and then eaten, and not available to us anymore. In the same way, we all know that with the decay of memory, vocabulary words in a second language that are studied at only one point in time and not rehearsed will fade away quickly too, melting in the heat of disuse like ice cream in the hot sun.

Kitano and Chiba did not ask us to accept that a one-time encounter with the words they tested meant language acquisition. They very responsibly went back and tested the students after a 2-week delay and found that the students had not forgotten everything, but they had forgotten most of what they had known. Since Kitano and Chiba deliberately picked less frequent words to test that they supposed their students would not know, and since that probably implies that the students did not encounter those words again, it is not surprising that they forgot most of what they had been able to produce immediately after learning the words and even after a 20-min distraction on the day of testing. 
I am sure almost all of you have seen Ebbinghaus' (1885) forgetting curve. If you recall, Ebbinghaus tested himself with nonsense strings of 13 randomly generated CVC syllables per list (so, e.g., one word might be "kat-bup-set-mak-tiplum-kak-vur-zip-lur-kul-wam-lal"). He memorized these "words" until he could remember them perfectly, then tested himself at different time periods to see how much he forgot. The results showed a big drop-off in ability at the beginning of the time period, but then the forgetting rate flattened out to an asymptote at a low percentage; however, it did not dissolve to zero. I would like to show you a graph I made that shows the forgetting sequence of a study by Bierling (1990), who taught students 100 less frequent words during their first 20 hours of an intensive Spanish class but then never mentioned the words again. They were words like madrastra "stepmother." Bierling then tested the students at different points to see how well they recalled these words that they did not use again (she ensured they did not by excluding words they said they had had contact with in the interim). This is the data for the productive test, and each line represents the data of one person. The $y$-axis ranges from $0 \%$ to $100 \%$, and the $x$-axis shows the time in weeks [five data points were tested: 0 (after the initial 20 h), 3.5, 7.0, 49, and 90] (Figure 1).

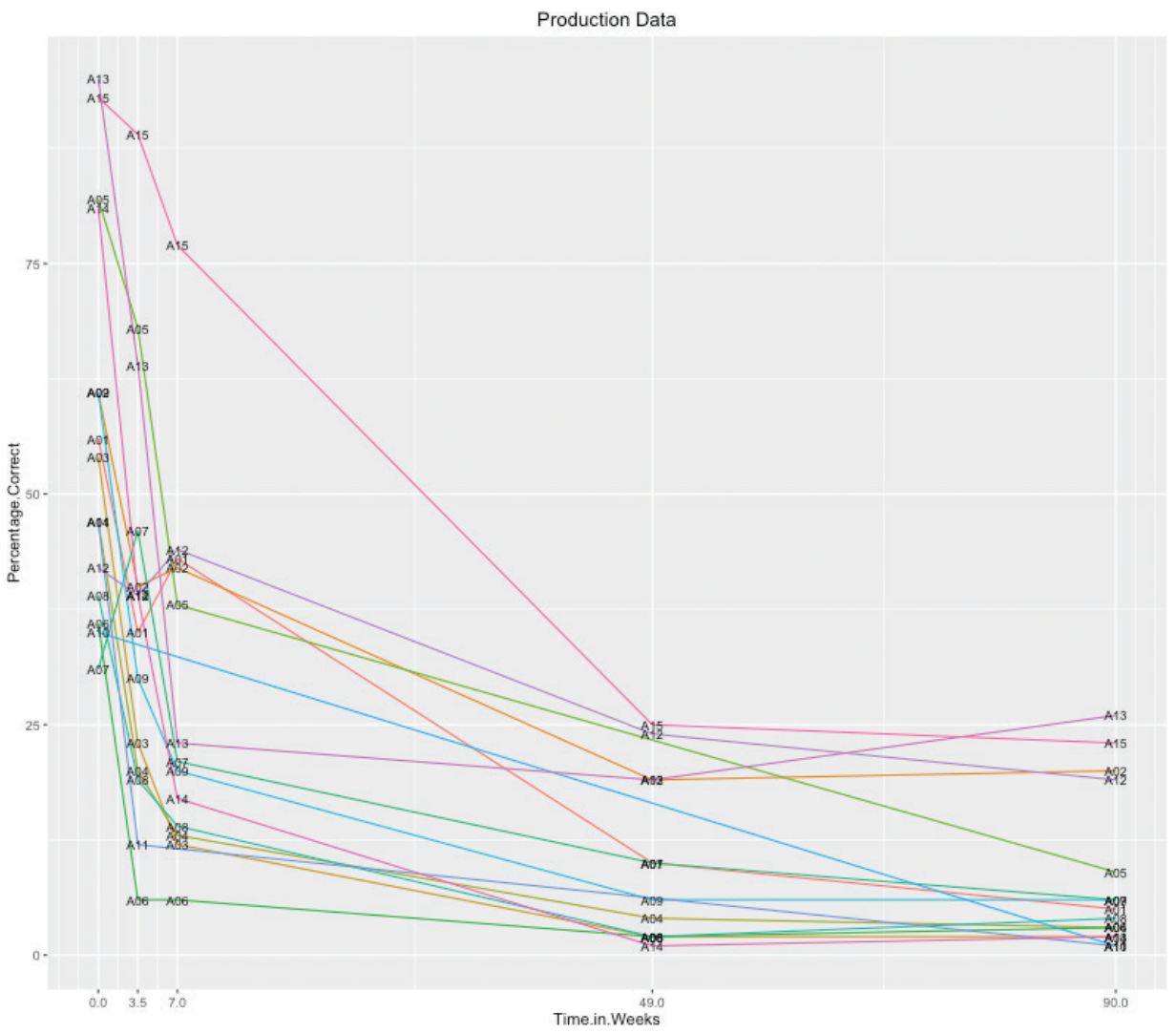

Figure 1. A parallel coordinate plot of Bierling's (1990) productive data. 
As you can see, most people were not able to produce more than $50 \%$ soon after the end of the semester, but even about a year later, this information had stabilized so that many people retained a little bit. So, this is similar to Kitano and Chiba's study, in that most of the students had forgotten these words that they had only spent a little time learning and had not subsequently used.

In fact, Kitano and Chiba did not include a figure in their study, but I have created a figure, similar to that of Bierling, which shows individual scores at the two testing periods for the group who learned with flashcards and the group who just looked at a list (Figure 2). By the way, here is the R code for the two graphs in Figure 2:

library(ggplot2)

ggplot(KitanoList, aes(Time, List, group=Student))+

geom_line (aes(color=Student))+geom_text(aes(label=Student), size=2)+

theme(legend.position="none") + ggtitle("List Learning")

ggplot(KitanoList, aes(Time, List, group=Student))+

+ geom_line $($ aes $($ color=Student $))+$ geom_text(aes (label=Student $),$ size=2) +

+ theme(legend.position="none")+ggtitle("List Learning")

Here we see that for the list learning group, most of the students are still retaining most of the information after $20 \mathrm{~min}$, while for the flashcard learning group, many are starting to lose ground. Actually, the list learning group started out with more even at the 0 point. So there is the point that the list learning group did better than the flashcard group, which I will return to. But the first point I want to make is that these data look very similar to Bierling's data. In other words, this study does not seem to be so much about language acquisition as about language forgetting. So maybe what is most important is not really the method you use to first learn a word, it is really the method that you use to

(a) List Learning

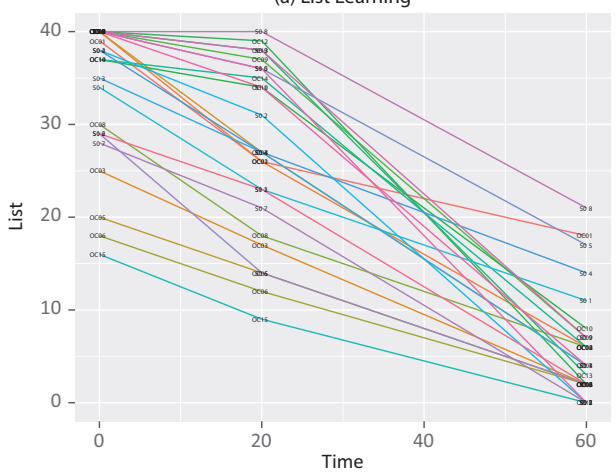

(b) Card Learning

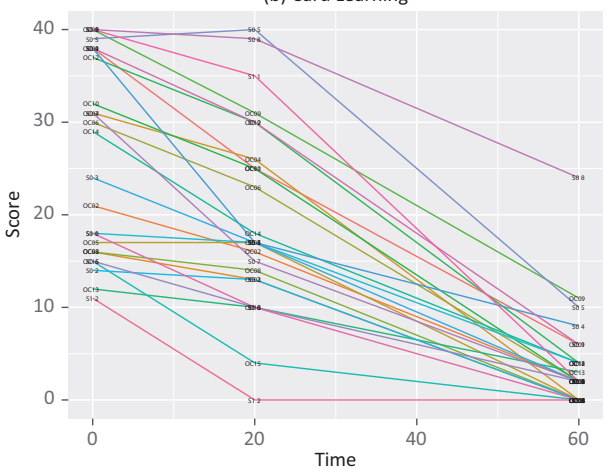

Figure 2. Parallel coordinate plots for Kitano and Chiba (this volume): (a) list learning and (b) card learning. 
retain a word, because retaining a word in order to use it in your daily life is what we are really interested in.

Coming back to the point that the list group did better than the card group, I was actually surprised that Kitano and Chiba did not find any difference between these two methods. If the methods were just to have a list of words to learn that could be covered up and guessed at as the student moved down the list, and to have flashcards that would also be guessed at, there really should not be much difference between the methods. However, Kitano mentioned (personal communication) that the list learning students were able to use a piece of paper and a pencil to write down the words, and when I asked her about it, she told me that in fact, all of the students had used the paper to practice writing the words as well. My initial thought was that since Kitano and Chiba's test was a production test, perhaps the list learning students were able to do better on the test than the flashcard group due to practice with production rather than superiority of list learning over flashcards. However, later Kitano mentioned that the flashcard students were able to use a paper and pencil to practice writing down the words as well, and again, all of them did, so that explanation does not appear to be valid. I am therefore left with no explanation for why list learning works better than flashcard learning in this study, and explaining why the list learning participants surpassed the flashcard participants could be an interesting idea for the authors to pursue. It would of course also be good to see the study replicated with different populations and circumstances.

So I guess my main thought about Kitano and Chiba's study is that it cannot really tell us much about acquiring a vocabulary word. Of course, this study does not stand alone in using this methodology. It is the methodology of numerous research designs for vocabulary, and in that sense, I do not want to single it out for any special mention of being problematic. What I would like to do is to note that the entire field of vocabulary studies ought to examine this issue very thoughtfully. Unless we want to admit that we are not interested in how students actually acquire vocabulary words and subsequently incorporate them into their lexical system, a research methodology of conducting a short-term treatment and then doing an immediate test and even a slightly delayed posttest should not be the way we go about investigating this question. Of course, proposals have been made regarding this issue (Jiang, 2000 discusses some of them, but that is beyond the scope of this article).

It may be much more difficult to teach students vocabulary that they indeed acquire than we have been heretofore assuming. A very informal study I did in a 15 -week English reading class comes to mind. The textbook I used asked the students to learn 20 words a week, and before the beginning of the semester, I gave the students a yes-no test to see how many of the words that were going to be studied they already knew. I then tested the students on their vocabulary words every week with a 10 -item test, using a fill-in-the-blanks format. Students were encouraged to review words by having a midterm that tested all the words up to that point and a final vocabulary test where students were told they had to know all of the words from the entire semester. Then, at the end of the semester, I administered the same yes-no test. My finding was that most students gained about three or four words over the course of the semester! This finding was astounding to me 
in its scarcity of learning and made me highly skeptical of how much vocabulary could/would be learned by students in the long run, even if they performed well in the short run.

\section{Practical Question 2: What vocabulary words should we study?}

At the end of his paper, Kida brings up a number of possibilities about how the TOPRA model could be applicable in answering practical questions about vocabulary acquisition. Kida suggests that different kinds of language processing could affect both the effectiveness of ways of learning words and the fluency with which they can learn to use those words. This is a very intriguing line of thinking, and clearly, more research should be done in this area.

So in thinking about how we should learn words, we are first faced with the choice of what words to learn. In Tim Stoeckel's paper, "An Examination of the NGSL," we find here again another highly practical implied suggestion for language learners, which is to use the NGSL. I was actually surprised to learn that this list is based on a British corpus (the Cambridge English Corpus), so matching up a section of Corpus of Contemporary American English (COCA) (Davies, 2008) and the NGSL was a very good idea. Stoeckel finds that the NGSL provides $4.32 \%$ better coverage than the General Service List (GSL) (83.66\% vs. $79.34 \%$ ), meaning that knowing the words from the NGSL will buy you a higher percentage of words from the 6-year section of COCA that was examined than if you only knew the words in the GSL. This is even more impressive given that the number of lemmas in the GSL is reported (at the NGSL website: www.newgeneralservicelist.org) to be 3623, while the number of lemmas in the NGSL is 2818. Higher coverage with fewer lemmas is quite a feat! And of course, Stoeckel tried the comparison out on a new corpus that neither one of the lists had been taken from, making it seem to be a very fair comparison.

So in practical terms, the NGSL seems to be a wonderful tool for students to use and for teachers to recommend for learning vocabulary. At the moment, the NGSL is available in Quizlet stacks for flashcard learning. Quizlet provides Spaced Repetition System (SRS) reviews but only if you pay the yearly fee, which is about \$20. I know a lot of students who learn Japanese like Anki for flashcards, and Anki has an SRS function as well, but it is free, and I see online that there are NGSL stacks for Anki as well.

Many of you are aware as well that there are analogues to the NGSL in Gardner and Davies' Academic Vocabulary List (AVL) (no date) and Brown, Culligan, and Phillips' (2013) New Academic Word List (NAWL). Both provide better coverage of academic corpora than the original Academic Word List created by Coxhead (Gardner \& Davies, 2014). If your students are fairly advanced and/or would benefit more from studying academically oriented words, then this list would also be a wonderful place for them to start. There are many resources for both lists. Emily Crandell's MA thesis (2017) details her process of creating Quizlet flashcards for the first 500 words of the AVL with translations into seven languages, including Japanese (also Mandarin, Korean, Arabic, Spanish, 
Portuguese, and Russian). There are links to flashcards in Quizlet with English definitions and in Memrise with Japanese definitions on Browne's NGSL site (www.newgeneralservicelist.org, then navigate to the NAWL).

I would like to suggest that any of you with free time might create a paid app for learning these words. I am personally using an app to learn kanji called WaniKani, and I find it much more compelling than my Quizlet cards. Why? I am not sure, but maybe because the program is all laid out for me and I just have to go in and spend 15-30 min every morning and night, and it feels like a game where I am progressing, rather than just a collection of decks of words. If you do not spend time on it, the work piles up so you feel you must do it every day to keep up. There are five levels and you move up or down the levels as you correctly or incorrectly input the words. With Quizlet if you use the SRS function, you do get some feedback about your overall progress, but my Quizlet suggests I learn only 10 words at a time. With WaniKani, it is like this train is moving on, you are going to have more words piling up every day if you do not keep up, and so it is more motivating to me. Also, with Quizlet there are a large number of stacks instead of having everything all in one program as I find in WaniKani. Perhaps the motivation of thinking you have to get your money's worth for something you paid for also factors in.

And some people might think that students would not want to study really basic words, but even though I speak Japanese pretty well, I have not minded doing WaniKani from the beginning because each level has a number of words that I never learned, or only have half-learned, so I felt even from the beginning it was helpful for improving my Japanese (Figures 3 and 4).

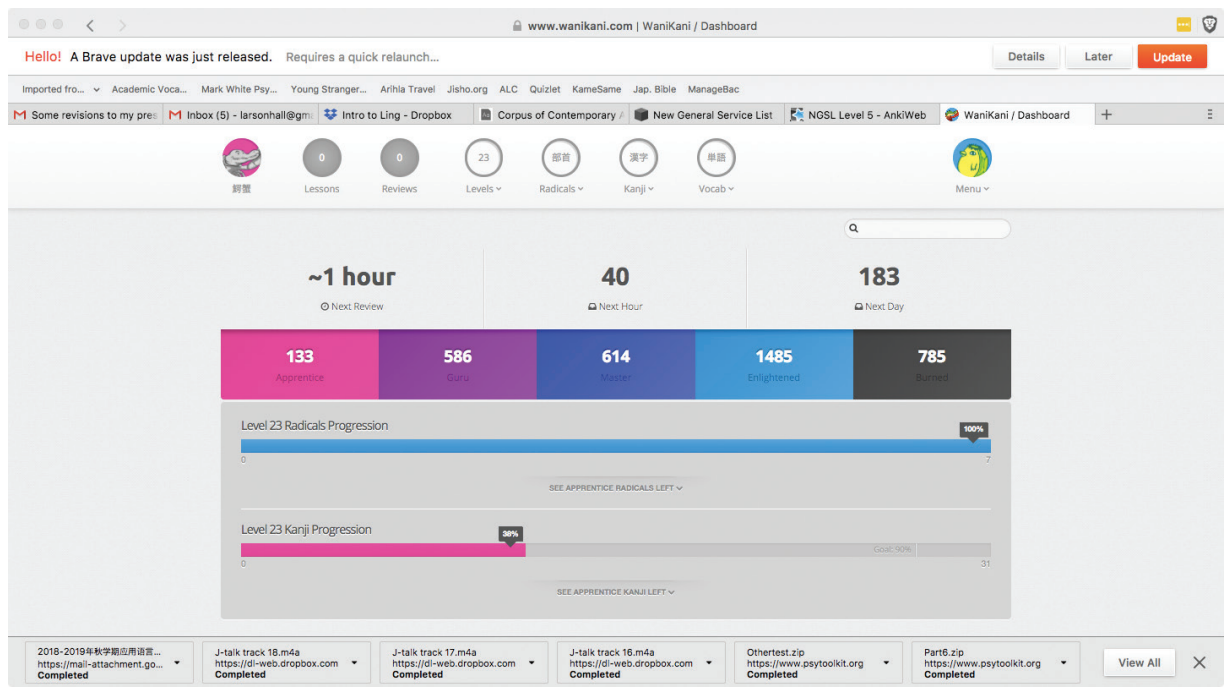

Figure 3. A screenshot of the WaniKani program showing how many words I have learned in each of the five spaced repetition intervals (the longest being the "burn" level, which takes at least 6 months to reach). 


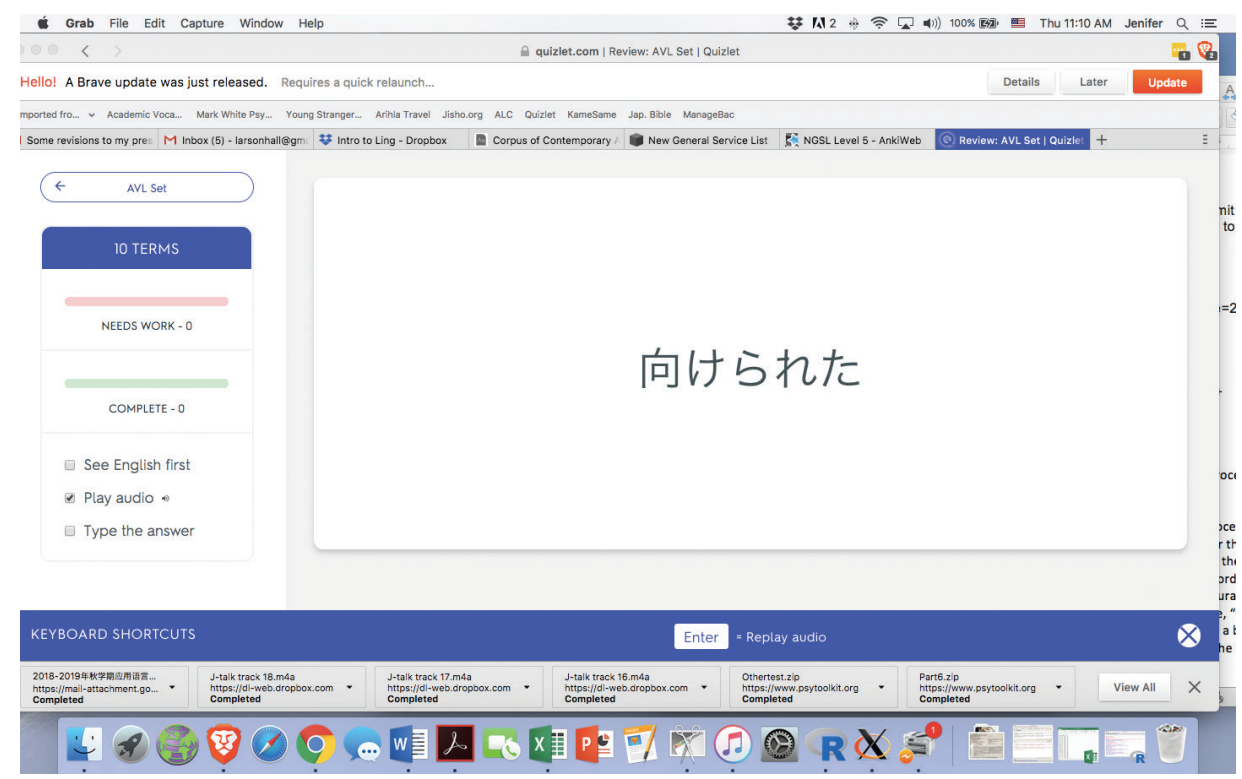

Figure 4. A screenshot of the Quizlet program.

\section{Practical Question 3: Are yes-no vocabulary tests really as good as they seem?}

Yes-no vocabulary tests have been around for a long time. There have been many tests and much work on verifying that this very simple format might be a good one to test vocabulary.

Raymond Stubbe's article, "Evaluating the efficacy of yes-no checklists tests to assess knowledge of multi-word units," is a very interesting look into this area. It seemed very concrete and practical to me, as I am currently working on a Japanese yes-no vocabulary test myself. Stubbe very astutely points out that there have been no checks on possible underestimation in yes-no tests, so I read very anxiously to find out the results of his test. He investigated the yes-no results by comparing them with an L2-L1 translation test, which seems to be a very direct way of testing whether the participants know the words. If I were him, I would justify this as the most reasonable and logical way of testing whether participants know the words, rather than saying it was the fastest measure. In fact, it seems funny to have to justify that translation tests are good indicators of which words students can understand receptively, since that is exactly what the translation test does, but I suppose justification must be made.

I think the biggest drawback to this research study is that it tries to look at too many issues but cannot really do all of the issues justice in the small amount of time that is available. I see in fact three very important issues raised in this paper:

(1) How much of a problem is underestimation of knowledge?

(2) Is a yes-no test a good tool for looking at knowledge of multi-word items?

(3) To what extent can correction for pseudowords help adjust for the difference between reported knowledge and actual knowledge? 
I think all of these are important questions and deserve a thorough inspection. However, in his introduction, Stubbe seems to be focusing only on question 2 , which is concerned with the efficacy of using yes-no checklists for multi-word items.

Stubbe notes that the issue of underestimation in yes-no tests has not been investigated previously. Researchers have worried more that students will overinflate their knowledge and say they know words that they are really not able to define. Stubbe, on the other hand, worried that students may indicate that they do not know words that they actually can give a definition for. However, his results showed, at least in the aggregate for single words (which have been the only kind of data used previously), that students responded with an "yes" to $77.2 \%$ of the 21 single words, while they were only able to correctly give a translation equivalent for $63.7 \%$ of those words, meaning they overestimated their knowledge instead of underestimating it. However, in looking at individual cases, Stubbe did find some instances where students said "no" on the yes-no test but then did in fact give a correct translation $-3.6 \%$ of the total number of answers. I would assume that this level of mismatch is simply a careless mistake, something like what Chomsky called the difference between competence and performance for language. From this study, I would conclude that we do not really have to worry very much about underestimation, and perhaps further study is not really necessary, but I may be wrong about that. The study was small and further investigation may reveal more pervasive underestimation.

For the issue of multi-word units, my feeling is that this issue is not really answered clearly enough in this paper to make strong conclusions. The whole area of multi-word units is clearly gaining attention in the field but is still nebulous, and not a lot of research traditions exist. Investigating knowledge of multi-word units or formulaic sequences with a yes-no test (and a translation test) is a really interesting idea, but I am not sure why single words and multi-word units were put into the same study. Stubbe said he wanted to compare them, but I am not sure there is anything comparable about them. We have different numbers of items, which Stubbe noted as a problem, and fixing that would be good, but probably it is more important to ascertain whether the words are of the same frequency level. We can talk about frequency level for words, but I am not sure we have the tools yet to actually talk about frequency levels for phrases. Presumably, different processes may be acting on words versus phrases, and in fact, Stubbe makes different recommendations about the use of yes-no tests and adjustments for false alarms with them. Likewise, the translation test gives the nearest evidence we can get to the actual recognition ability of the words, and we see that the correlation between the yes-no test and the recognition test is, on the surface of it, somewhat higher for single words than for multi-word units ( 0.53 vs. 0.38 of Stubbe's paper from Table 4, unadjusted scores), although this difference narrows when scores are adjusted for false alarms (0.39 vs. 0.31).

I guess I am also worried that yes-no tests even used with single words have a number of problems that we should not forget. I know they have been used successfully in many cases, but a little looking can uncover some unsettling research on yes-no tests. For example, Stubbe noted that Eyckmans (2004) also compared L2-to-L1 translation as a criterion measure to examine the 
validity of yes-no tests, but I was wondering what the results of that study were. This paper was Eyckmans doctoral thesis, and she looked at the yes-no test for French learners of Dutch. Eyckmans actually did seven different experiments because she found a lot of unreliability in the yes-no test and low correlations with the translation test. Eyckmans states that "whenever a substantial false alarm rate is encountered in the data, this is evidence of the fact that the participants perform a different task than is expected of them hence the validity of the test becomes doubtful. In these cases, cases, the competence that is measured with the Yes/No Test does not correlate well with word recognition as measured by a translation task." I am afraid the testing issues Eyckmans brings up are too complicated to discuss here, but we should keep in mind that although yes-no tests do seem to work well sometimes, they also seem to have some serious drawbacks as well. So the fact that Stubbe found some substantial false alarm rates also has me worried that the yes-no test may not have worked well enough in this administration of his test to measure even single words, much less multi-word units.

The last issue that came to the forefront here was the third one I mentioned, which is whether adjustments for false alarms can effectively reduce the difference between reported knowledge and actual knowledge, and I think that is a difficult question that deserves further consideration. Again, Eyckman's (2004) thesis does explore this in depth and opines that more sophisticated techniques might need to be applied to the data in order to better adjust for false alarms. Clearly that was not done with these data but if recommendations are going to be made about adjustments with one type of data over another, I think it might be worth a look.

If we have a moment to indulge me, I would like to bring up just one more issue in regard to this study. That is the issue of outliers. Stubbe noted that one participant chose 11 out of the 15 pseudowords, so he was removed from the data set. Stubbe also did some analyses with only 10 of the 15 false alarm words included. I know it is very tempting to the data of (participants) whose results look very abnormal, but statisticians say that just removing what seem like outliers by using our own judgments will result in a loss of independence in the data. It is better to use a principled approach to removing outliers, which involves robust estimators. So I made up a scatterplot of Stubbe's data, comparing the scores on all 30 of his items for the yes-no test versus the translation test. Here is the scatterplot and the R code I used (Figure 5):

scatterplot(Tr.30.Score $\sim$ YN.Scores.30, regLine=FALSE, smooth=FALSE, boxplots $=$ 'xy',

jitter=list $(x=1, y=1), x l a b=" Y e s-N o$ test score", ylab="Translation test score", main="Stubbe data for all 30 items and all participants", $x \lim =\operatorname{range}(\mathrm{c}(0,30))$, ylim=range $(\mathrm{c}(0,30))$, cex $=1.6$,

data $=$ Stubbe)

Now looking at this, we can see there is definitely a positive relationship between scores on the yes-no test and scores on the translation test, although 


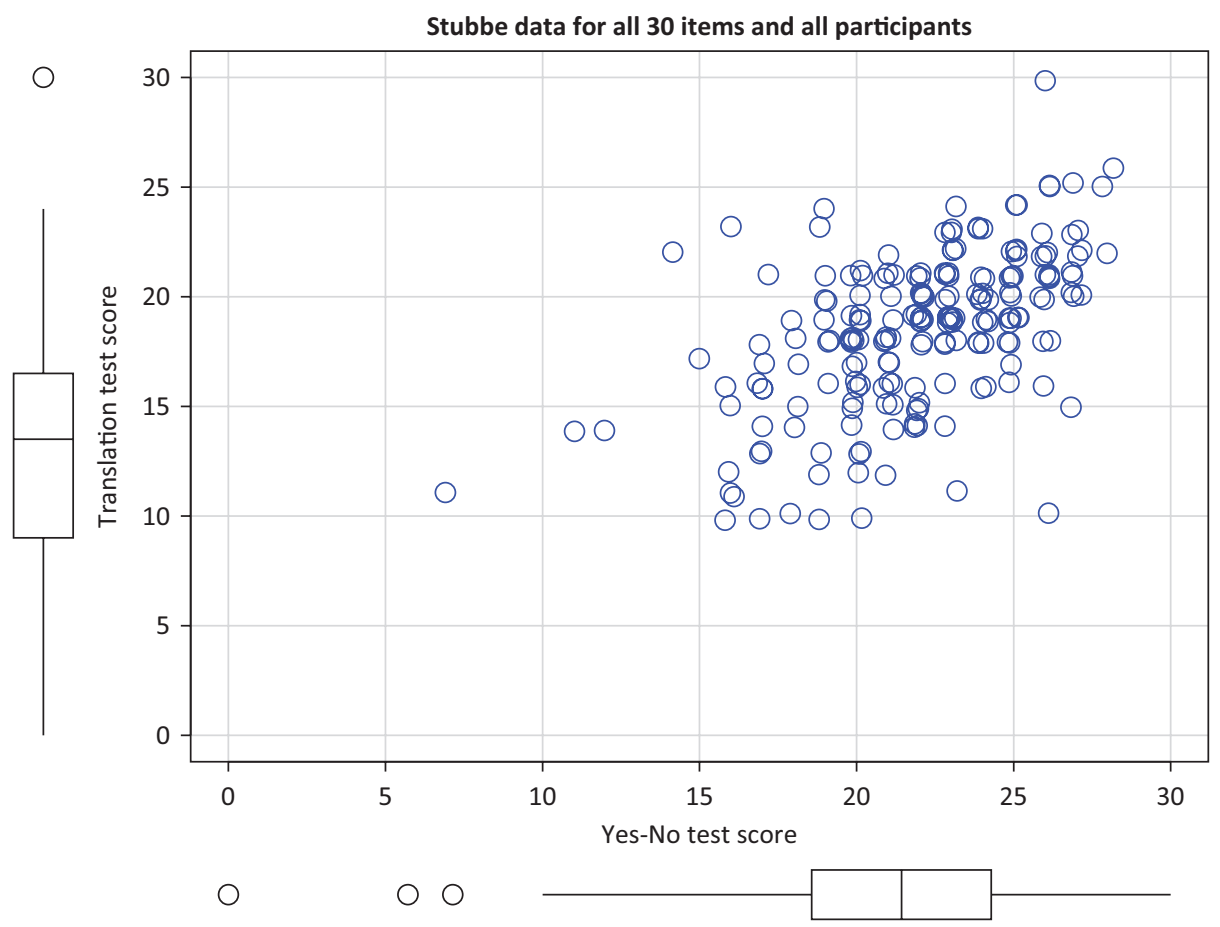

Figure 5. Normal scatterplot of Stubbe's data plotting yes-no test scores against translation test scores.

we do not have data along the whole length of our regression line since most students were near the upper end of the scale (that might be another issue in this test). I am not sure if the person who had 11 false alarms is in these data or not, but if you look at these data, you will probably think that you can identify some outliers.

Next I want to show you a scatterplot with what are considered the "robust" data, using a tolerance ellipse plot, where the ellipse is defined by those data points whose distance is equal to the square root of the 0.975 chisquare quantile with 2 degrees of freedom. Here is the R code and the scatterplot (Figure 6):

library(robustbase)

covPlot(cbind(Stubbe\$YN.Scores.30, Stubbe\$Tr.30.Score),which="tolEllipsePlot", classic $=\mathrm{T}$, cor $=\mathrm{T}$ )

There may be more outliers here than what you had considered! What I want you to think about is that you may not be very good at identifying what is really an outlier and what is not, especially when you have multivariate data. So let us allow mathematical formulas to help us figure it out by using robust statistics. 


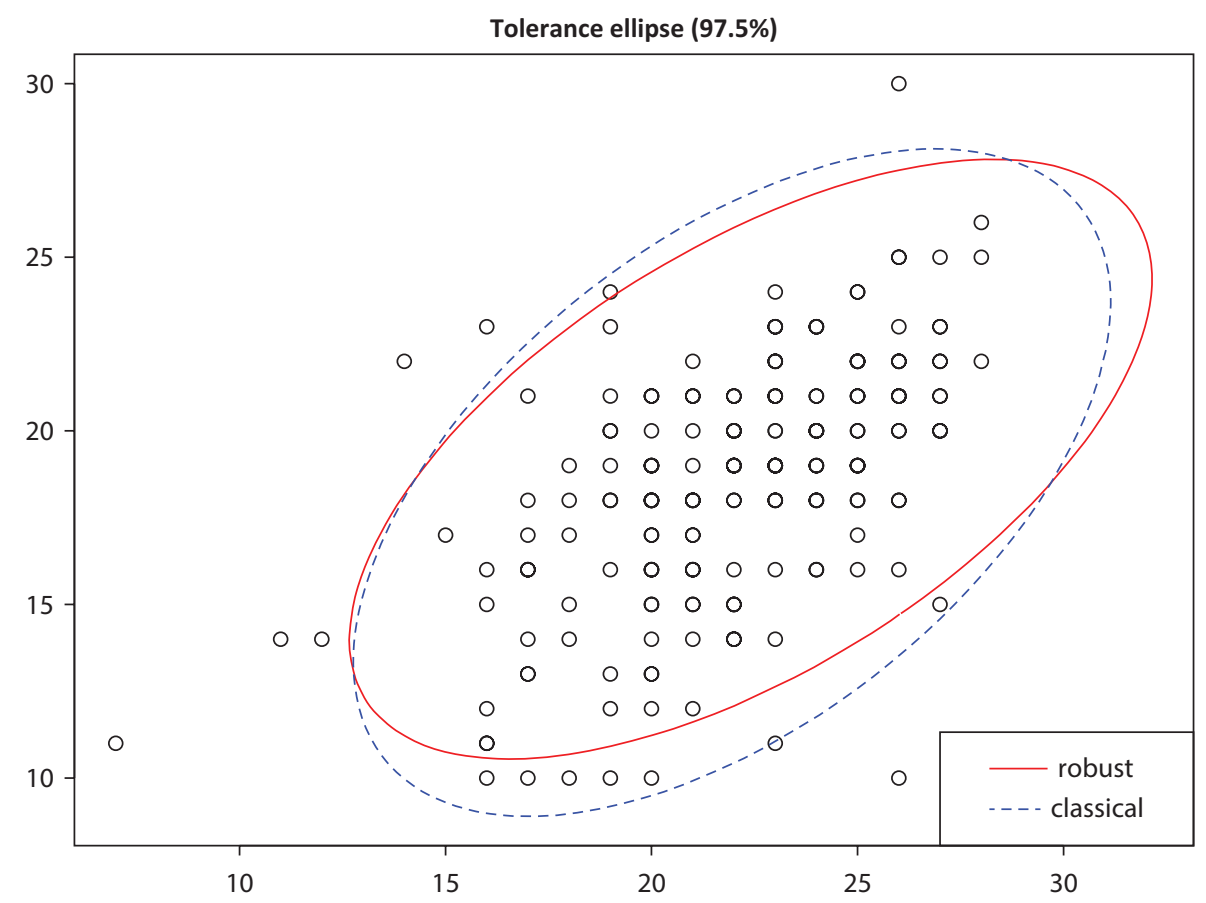

Figure 6. Robust scatterplot of Stubbe's data plotting yes-no test scores against translation test scores.

\section{Conclusion}

The four papers we heard today have presented us with a variety of ideas to think about and challenged us to apply them to real-life problems. As a field, clearly we need to think about a number of important big-picture ideas as we seek to refine the practical techniques which are being used in our classrooms and taught to language teachers. Novices to the area of vocabulary studies almost invariably ask the question, "How can vocabulary be learned most effectively," but today we have seen that that question involves many different components, starting with how we define "learning." We have also seen ideas about how that learning can be tested and what words and what forms of words students should concentrate on learning. The types of processing that go on while students learn words should also be taken into account and explored. As our research on vocabulary studies goes on, we continue to make progress on how, what and when to learn vocabulary, but we also open up many new questions and avenues for continued research.

\section{References}

Bierling, R.M. (1990). Foreign language vocabulary attrition: A study of college-level Spanish students over an 18-month period. Unpublished Ph.D. thesis. Michigan State University. 
Brown, C., Culligan, B., \& Phillips, J. (2013). New Academic Word List. Retrieved from http://www.newgeneralservicelist.org/nawl-new-academic-word-list/

Crandell, E.R. (2017). Quizlet flashcards for the first 500 words of the Academic Vocabulary List. MA Thesis, Brigham Young University. Retrieved from https:// scholarsarchive.byu.edu/cgi/viewcontent.cgi?article $=7335 \&$ context $=$ etd

Davies, M. (2008). The Corpus of Contemporary American English (COCA): 560 million words, 1990-present. Retrieved from http://corpus.byu.edu/coca/

Ebbinghaus, H. (1885). Memory: A contribution to experimental psychology (H.A. Ruger \& C.E. Bussenius, Trans.). New York: Teacher's College, Columbia.

Eyckmans, J. (2004). Measuring receptive vocabulary size: Reliability and validity of the Yes/No vocabulary test for French-speaking learners of Dutch. Ph.D. dissertation from Katholieke Universiteit Nijmegen.

Gardner, D., \& Davies, M. (2014). A new Academic Vocabulary List. Applied Linguistics, 35(3), 305-327. doi: 10.1093/applin/amt015.

Gardner, D., \& Davies, M. (no date). The Academic Vocabulary List. Retrieved from https://www.academicvocabulary.info/samples/general-core.pdf

Jiang, N. (2000). Lexical representation and development in a second language. Applied Linguistics, 21, 47-77. doi: 10.1093/applin/21.1.47.

Kida, S., \& Barcroft, J. (2017). Semantic and structural tasks for the mapping component of L2 vocabulary learning: Testing the TOPRA model from a new angle. Studies in Second Language Acquisition, 40(3), 477-502. doi: $10.1017 / \mathrm{S} 0272263117000146$. 